\title{
Infantile Colic in Infants Aged One-Six Months and the Practices of Mothers for Colic
}

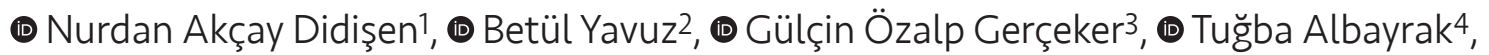 \\ (1) Meryem Atak5, @ Didar Zümrüt Başbakkal6 \\ ${ }^{1}$ Ege University Faculty of Nursing, Department of Pediatric Nursing, İzmir, Turkey \\ ${ }^{2}$ Kutahya University of Health Sciences, Faculty of Health Sciences, Department of Pediatric Nursing, Kütahya, Turkey \\ ${ }^{3}$ Dokuz Eylül University Faculty of Nursing, Department of Pediatric Nursing, İzmir, Turkey \\ ${ }^{4}$ Adnan Menderes University Faculty of Nursing, Department of Pediatric Nursing, Aydın, Turkey \\ 5 Uludağ University Faculty of Nursing, Department of Pediatric Nursing, Bursa, Turkey \\ ${ }^{6}$ Ege University Faculty of Nursing, Department of Pediatric Nursing, İzmir, Turkey
}

\section{ABSTRACT}

Aim: The aims of this study were to explore the infantile colic in infants from 1-6 months of age, and the mother's practices to eliminate colic and the relationships between infantile colic scores and sample characteristics.

Materials and Methods: This descriptive study included 232 mothers of infants who were admitted to the hospital for child monitoring at two university hospitals in the Aegean region. Information on demographics, colic characteristics, and practices of mothers to eliminate colic was collected.

Results: According to reports of the mothers, $67.2 \%$ of the infants had colic, and $28.5 \%$ of the infants met all of the Wessel criteria. The average scale score of infantile colic was $65.2 \pm 12.6$. To eliminate the colic, $67.6 \%$ of the mothers held their infants on their lap, $68.7 \%$ rocked them, $63.2 \%$ changed the position of their infants, $57.4 \%$ massaged the infants' bellies, and $37.1 \%$ stated that they used a warm application.

Conclusion: One out of every three-four babies in the study met the diagnosis of infantile colic according to Wessel criteria's. The average score obtained from the infantile colic scale is quite high. Mothers usually use behavioral methods to prevent and reduce colic symptoms, they also use pharmacological and traditional methods in this study.

Keywords: Infantile colic, mother, practices

\section{Introduction}

Infantile colic is observed in $10-30 \%$ of infants in the first 3 months of life (1-3). Wessel et al. (4) stated that "paroxysmal fussing/infantile colic" is a somatic response to tension in the environment. Infantile colic is characterized by uncontrollable crying episodes in healthy infants, especially in those less than 3 months of age (5). Infantile colic is related to many conditions, its pathogenesis is not completely known and has different definitions (2-6,7). There are many methods for preventing infantile colic. In addition to behavioral methods such as rocking and massage, pharmacological and traditional approaches can be used (2-9). It is a very important topic that affects the family deeply and especially makes them feel insufficient (10-12). 
The crying episodes can last more than 3 hours per day, and 3 days per week, for at least 3 weeks (5). This "rule of 3 " description is the most widely accepted description, and was introduced by Wessel et al. (4) We also used this "rule of 3 " description to diagnose colic in this study. There is no single definition of colic. Wessel's criteria can be used, and some researchers adopt behavioral signs of infants and parental reports to determine infantile colic (1-13). The study by Helseth and Begnum (13) found that infants identified by parents and nurses cried more than 3 hours a day and crying occurred on more than 3 days in any 1 week and lasted for more than 3 weeks similar to Wessel's criteria.

In addition to these descriptions, many studies indicate that infantile colic is seen during the first 3 months of life when they are between 3 weeks and 3 months old especially in the afternoons (after 3 o'clock) or at night (1-7). The diagnostic criteria for infantile colic were also determined by Benninga et al. (6). There are some differences in this definition such as colic symptoms' start/stop time $(<5$ months), not being preventable or resolvable by caregivers, and caregiver reports about infants crying for 3 or more hours per day on 3 or more days within a 7-day period (6). Beside these definitions, the Infant Colic scale can be used to diagnose colic and it includes five possible explanations related to colic such as cow's milk/soy protein allergy or intolerance, immature gastrointestinal system, immature central nervous system, difficult infant temperament, and parent-infant interaction problems (14).

\section{The aims of this study were:}

- to diagnose infantile colic in infants aged 1-6 months.

- to examine mothers' practices in the elimination of colic.

\section{Material and Methods}

\section{Setting and Study Design}

In this descriptive and cross-sectional study, 232 mothers of infants between 1 and 6 months of age who requested their children to be monitored at two university hospitals between August 2015 and October 2015 were enrolled in the study. The inclusion criteria were as follows: mothers who volunteered to participate in the study, babies aged 1-6 months, babies who did not have a chronic disease, and mothers who were primarily responsible for their baby's care.

\section{Instruments}

\section{Sociodemographic and Colic Characteristics Form}

This form includes items questioning the babies' sociodemographic characteristics such as age, gender, whether the baby is breastfed or not, if it is breastfed exclusively or breastfed and supplemented with formula, the use of a pacifier, and the type of baby bottle. The form also includes items questioning the mothers' sociodemographic characteristics such as age, educational status, working status, income, and their number of children. This form also includes a place for the mothers' statements about whether their infants suffer from colic, the nature of their colic, crying spells, the nutrients that cause colic according to the mothers' opinion, whether the mothers eat these foods or not, and the practices used by the mothers to eliminate colic.

The nature of colic included in the Wessel (4) criteria are as follows: the crying episodes last more than 3 hours per day, more than 3 days per week, for at least 3 weeks. It also states that the crying episodes take place during the first 3 months of life - when they are between 3 weeks and 3 months old especially in the afternoons (after 3 o'clock) or at nights.

\section{The Infant Colic Scale}

This scale was developed by Cirgin Ellett et al. (14) to diagnose colic in infants. This scale includes 22 items in 5 subscales: (1) Cow's Milk/Soy Protein Allergy/Intolerance (2 items), (2) Immature Gastrointestinal System (4 items), (3) Immature Central Nervous System (8 items), (4) Difficult Infant Temperament (4 items), and (5) Parent-Infant Interaction and Problematic Infant (4 items). It was reported that in the Turkish validity and reliability study of this scale, item 5 (Baby vomits milk that looks like it did before it was drunk) and item 6 (Baby has no difficulty passing stool) of the immature digestive system subscale and item 11 (Baby eats at the same time every day) of the immature central nervous system subscale were removed. Consequently, the Turkish form of this scale only consists of a total of 19 items. The items are evaluated on a 6-point Likert-type scale, ranging from 1 (strongly disagree) to 6 (strongly agree). A low total score is positive for showing colic, and a high score indicates negative (14). The reliability and validity study of the Turkish version of the scale was conducted by Çetinkaya and Başbakkal (15). While the Cronbach's alpha coefficient ranged from 0.55 to 0.89 for the subscales, it was 0.73 for the total scale. The 19-item and 5 subscale Infant Colic Scale was determined to be valid and reliable for the Turkish population (15).

\section{Data Collection}

The researchers reached out to the mothers in outpatient waiting areas. The researchers asked the mothers of infants who came to the hospital for child monitoring if their 
babies had a chronic disease, and were between 1 and 6 months of age. If the baby did not have a chronic disease and was 1-6 months of age, the researchers explained the study aims to the mother, and obtained written informed consent. After written consent was obtained, sociodemographic information, data relating to the infantile colic of the baby and the mother's practices to eliminate the colic were collected using the "Sociodemographic and Colic Characteristics form", and "The Infant Colic scale". The data were collected from the mothers in outpatient waiting areas in the hospital setting via face to face interviews.

\section{Statistical Analysis}

The data were analyzed using the SPSS 23.0 (SPSS, Inc., Chicago, IL) for Windows. Sample characteristics were summarized using means and standard deviations for continuous variables and proportions for categoric variables. The independent sample t-test and ANOVA test were used to investigate statistical difference between infantile colic scores and other variables. An alpha level of $p<0.05$ was considered statistically significant.

\section{Ethics}

The study was approved by the Ethics Committee of Faculty (IRB: 2015-82). Written informed consent was obtained from the participants before enrollment.

\section{Results}

The study included 232 infants who met the inclusion criteria. The mean age of the infants was $3.6 \pm 1.8$ months. Of the infants, $54.3 \%$ were male, $56.9 \%$ were breastfed exclusively, $58.2 \%$ did not use a feeding bottle, and $46.1 \%$ did not use a pacifier. The mean age of the mothers was $28.6 \pm 5.3$ years. Of the mothers, $42.2 \%$ were primary school graduates, and $57 \%$ had 1 child (Table I).

According to the mothers' statements, $67.2 \%$ of the infants suffered from colic, $41.3 \%$ continuously cried for more than 3 hours per day, $70.5 \%$ had crying spells 3 days per week, $50.6 \%$ cried for at least 3 weeks. Of them, $28.5 \%$ met all of the Wessel criteria. Of the infants, $67.6 \%$ started to cry when they were between 3 weeks and 3 months old (during the first 3 months of life), and $70.1 \%$ generally cried in the afternoons or at nights.

The breastfeeding mothers reported that dry legumes (64.7\%), milk (12.9\%), and carbonated beverages (23.7\%) caused colic in their infants. Of the mothers, $70.7 \%$ stated that in their opinion, they ate certain foods that caused the colic. To prevent colic, of them, $67.6 \%$ held the infants on their laps, $68.7 \%$ rocked the infants, $53.4 \%$ gave the infants abdominal massage, $43.1 \%$ took the infant to a calm and dimly lit environment, and $40.1 \%$ had their infants drink olive oil (Table II).

The mean score obtained from the overall scale was 65.2 \pm 12.6 (minimum: 35, maximum: 98) (Table III). The total mean score had statistically significant differences for colic in terms of the mothers' statements ( $t=3.064, p=0.002)$, the infant's age $(p=0.000)$, and the mother's education level ( $F=3.338, p=0.020)$; however, the total mean score was found to have no statistically significant differences in terms of the infant's gender ( $t=-0.242, p=0.809)$, the way of feeding $(F=1.323, p=0.268)$, the use of a feeding bottle ( $t=-$ $0.685, p=0.494)$, the use of a pacifier $(t=0.452, p=0.652)$, the mother's working status ( $t=-0.680, p=0.497)$, the number of children $(F=2.423, p=0.091)$, and the consumption of foods that cause flatulence $(t=0.509, p=0.611)$.

\begin{tabular}{|c|c|c|}
\hline & $\mathbf{n}$ & $\%$ \\
\hline \multicolumn{3}{|l|}{ Infant's gender } \\
\hline $\begin{array}{l}\text { Female } \\
\text { Male }\end{array}$ & $\begin{array}{l}106 \\
126\end{array}$ & $\begin{array}{l}45.7 \\
54.3\end{array}$ \\
\hline Infant's age (month) & \multicolumn{2}{|c|}{$\begin{array}{l}M \pm S D(\min -\max ) \\
3.6 \pm 1.8(1-6)\end{array}$} \\
\hline Breastfed & $\mathrm{n}$ & $\%$ \\
\hline $\begin{array}{l}\text { Yes } \\
\text { No }\end{array}$ & $\begin{array}{l}219 \\
13\end{array}$ & $\begin{array}{l}94.4 \\
5.6\end{array}$ \\
\hline \multicolumn{3}{|l|}{ Way of feeding the infant } \\
\hline $\begin{array}{l}\text { Breast milk only } \\
\text { Breast milk and formula } \\
\text { Formula }\end{array}$ & $\begin{array}{l}132 \\
87 \\
13\end{array}$ & $\begin{array}{l}56.9 \\
37.5 \\
5.6\end{array}$ \\
\hline \multicolumn{3}{|l|}{ Using a feeding bottle } \\
\hline $\begin{array}{l}\text { Yes } \\
\text { No }\end{array}$ & $\begin{array}{l}97 \\
135\end{array}$ & $\begin{array}{l}41.8 \\
58.2\end{array}$ \\
\hline \multicolumn{3}{|l|}{ Using a pacifier } \\
\hline $\begin{array}{l}\text { Yes } \\
\text { No }\end{array}$ & $\begin{array}{l}125 \\
107\end{array}$ & $\begin{array}{l}53.9 \\
46.1\end{array}$ \\
\hline Mothers age & \multicolumn{2}{|c|}{$\begin{array}{l}M \pm S D(\min -\max ) \\
28.6 \pm 5.3(18-43)\end{array}$} \\
\hline $\begin{array}{l}\text { Education level } \\
\text { Literate } \\
\text { Primary school } \\
\text { High school } \\
\text { University/Graduate school }\end{array}$ & $\begin{array}{l}\mathbf{n} \\
16 \\
98 \\
49 \\
69\end{array}$ & $\begin{array}{l}\% \\
6.9 \\
42.2 \\
21.1 \\
29.8\end{array}$ \\
\hline \multicolumn{3}{|l|}{ Working status } \\
\hline $\begin{array}{l}\text { Yes } \\
\text { No }\end{array}$ & $\begin{array}{l}62 \\
170\end{array}$ & $\begin{array}{l}26.7 \\
73.3\end{array}$ \\
\hline Number of children & \multicolumn{2}{|c|}{$\begin{array}{l}\mathbf{M} \pm \mathbf{S D}(\min -\max ) \\
1.5 \pm 0.7(1-3)\end{array}$} \\
\hline
\end{tabular}


Table II. Infantile colic in the infants and mothers' practices regarding infantile colic

\begin{tabular}{|c|c|c|}
\hline & $\mathbf{n}$ & $\%$ \\
\hline \multicolumn{3}{|c|}{$\begin{array}{l}\text { Mothers' statements about whether their infants suffer } \\
\text { from colic }\end{array}$} \\
\hline $\begin{array}{l}\text { Yes } \\
\text { No }\end{array}$ & $\begin{array}{l}156 \\
76\end{array}$ & $\begin{array}{l}67.2 \\
32.8\end{array}$ \\
\hline \multicolumn{3}{|l|}{ Nature of the colic } \\
\hline $\begin{array}{l}\text { The infant was continuously crying more than } \\
3 \text { hours per day* }\end{array}$ & 74 & 41.3 \\
\hline The infants had crying spells 3 days per week* & 124 & 70.5 \\
\hline $\begin{array}{l}\text { The infants had been crying for at least } 3 \\
\text { weeks* }\end{array}$ & 89 & 50.6 \\
\hline $\begin{array}{l}\text { The infants generally started to cry when they } \\
\text { were } 3 \text { weeks or } 3 \text { months old/ during the first } \\
3 \text { months }\end{array}$ & 121 & 67.6 \\
\hline $\begin{array}{l}\text { The infants generally cry in the afternoon } \\
\text { (after } 3 \text { o'clock) or at night }\end{array}$ & 124 & 70.1 \\
\hline
\end{tabular}

Infants' status of having colic according to all of the Wessel criteria

\begin{tabular}{|l|l|l}
\hline Yes & 66 & 28.5 \\
No & 166 & 71.5
\end{tabular}

The nutrients that cause colic according to the mothers' opinion

\begin{tabular}{l|l|l} 
Legumes (chickpea, bean, lentil) & 150 & 64.7 \\
Carbonated beverages & 55 & 23.7 \\
Milk & 30 & 12.9 \\
Broccoli, cabbage, cauliflower & 33 & 14.2 \\
Spicy and hot spicy foods & 13 & 5.6
\end{tabular}

Do the breastfeeding mothers eat the foods which they consider a cause of colic?

\begin{tabular}{|l|l|l|}
\hline Yes & 164 & 70.7 \\
No & 68 & 29.3 \\
\hline
\end{tabular}

\section{Practices used by the mothers to eliminate colic Behavioral}

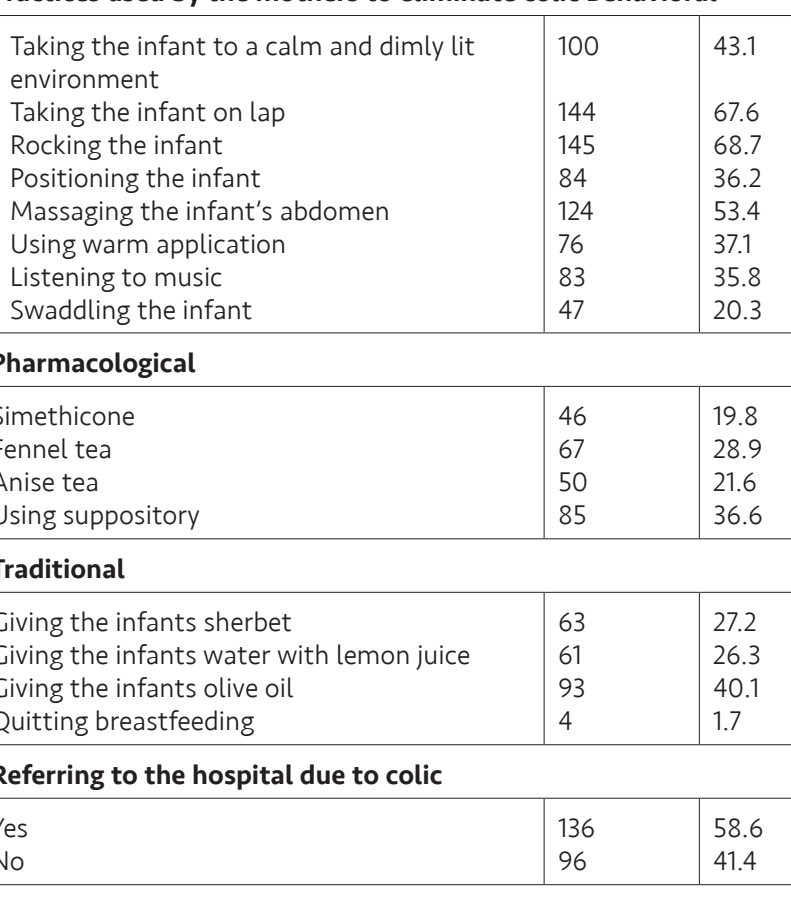

*Wessel Criteria's; 3 hours per day, and 3 days per week, for at least 3 weeks

\begin{tabular}{|l|l|}
\hline \multicolumn{2}{|l|}{ Table III. Infant colic scale scores } \\
\hline Subscales & $\begin{array}{l}\text { M } \pm \text { SD } \\
\text { (Min-Max) }\end{array}$ \\
\hline Cow's Milk/Soy Protein Allergy/Intolerance & $9.1 \pm 2.8(2-12)$ \\
\hline Immature Gastrointestinal System & $6.6 \pm 2.5(2-12)$ \\
\hline Immature Central Nervous System & $25.1 \pm 6.0(10-40)$ \\
\hline Difficult Infant Temperament & $13.8 \pm 4.4(4-24)$ \\
\hline Parent-Infant Interaction +Problem Infant & $10.4 \pm 3.2(4-21)$ \\
\hline Total scale & $65.2 \pm 12.6(35-98)$ \\
\hline M: Mean, SD: Standard deviation, Min: Minimum, Max: Maximum \\
\hline
\end{tabular}

The total mean score on the scale was found to have statistically significant differences with the Wessel criteria; "the infants cried persistently for more than 3 hours per day" ( $t=1.765, p=0.049)$, "the infants had crying spells 3 days per week" ( $t=4.589, p=0.000)$, and "the infants cried for at least 3 weeks" ( $t=2.278, p=0.024)$. No statistically significant difference was found between the mean score on the scale and meeting all of the Wessel criteria ( $t=1.663$, $p=0.098$ ). In addition, the total mean score on the scale was found to have statistically significant differences with "the infants generally started to cry when they were between 3 weeks and 3 months old" ( $t=2.898, p=0.004)$, and "the infants generally cry during the afternoon (after 3 p.m.) or at night" (t=2.396, $p=0.017)$.

\section{Discussion}

Infantile colic can be a cause of maternal distress, the effect of which remains unclear due to the self-limiting nature of the illness. Of the mothers in this study, $67.2 \%$ answered "yes" to the question, "Do you think your baby is suffering from colic?". Of the infants, $28.5 \%$ met all of the Wessel criteria. In another study, according to the mothers' statements, the infantile colic incidence was $80.1 \%$, but the total incidence assessed using the Wessel's criteria was $16.3 \%$ (16). This may be due to the definition of the illness, the educational status of the mother, and the subjective assessment of the mother caused by the psychological changes she experiences.

Karabel et al. (17) identified a history of colic in $75 \%$ of 170 infants aged between 6 and 9 months, and found no difference between the infants who did or did not meet the definition of colic according to the Wessel criteria in terms of birth weight, gender, type of delivery, accompanying diseases, maternal care and food supplementation in the first 3 months, food allergy, exposure to smoking, or mothers' age. The present study also did not reveal a significant difference between the mean score on the colic 
scale and the infants' gender, way of feeding, use of a feeding bottle, use of a pacifier, mother's working status, number of children, or eating foods that cause flatulence.

There is no consensus on whether the manner of feeding and the development of colic are related to each other or not. However, it is known that breastfeeding for the first six months is a preventive factor against infantile colic. Karabel et al. (17) revealed that the incidence of colic was $74 \%$ among breastfed infants and $26 \%$ among the infants who were not breastfed or fed with formula along with breast milk, and found no significant differences between the incidence of colic and the manner of providing nutrition. In the present study, almost all of the infants were breastfed, and no significant difference was found between the manner of providing nutrition and mean scores on The Colic scale. This result is similar to the results of other studies and provides a significant contribution to the literature. Lucassen et al. (18) stated that gender, socioeconomic level, type of feeding, family history of atopy, and maternal smoking were not associated with colic. Exclusive breastfeeding is associated with reduced colic, and nocturnal-breast milk contains substantial levels of melatonin (19).

The mothers in the present study mostly held their infants on their laps (67.6\%), used pacifiers (53.9\%), took their infants to a calm and dimly lit environment $(43.1 \%)$, rocked them $(68.7 \%)$, gave the infants abdominal massage (53.4\%), played music for their infants (35.8\%), and swaddled their infants (20.3\%) to eliminate colic. Çiftçi and Arıkan (20) stated in their studies that mothers held their infant in their arms (87.9\%), used massage (80.9\%), repositioned and rocked the infant $(79.4 \%)$, brought the infant to a dark quiet room (48.2\%), and warmed the infant (41.1\%). Behavioral methods noted in this study were similar to those seen in other studies. The detection of these methods is also a guide for nurses and provides important results in directing mothers to manage colic symptoms. Swaddling is a traditional practice, and it is used to reduce infantile colic. However, swaddled infants are under an increased risk of sudden infant death syndrome, and lateterm dysplasia of the hip. Therefore, mothers should be advised to avoid placing their swaddled infants in straight, lateral positions while they are sleeping $(20,21)$.

The most commonly known pharmacological approach to reducing infantile colic is the use of simethicone, which increases intestinal movements and reduces the development of gas, thereby reducing colic attacks. In the present study, the rate of simethicone use was $19.8 \%$ (22). Karabel et al. (17) reported that the pharmacological treatments most frequently recommended by doctors were copper natural, simethicone drops, Nurse Harvey's herbal oil, fennel oil, and apple oil, respectively. However, they found no difference between the groups who did or did not receive pharmacological treatment in terms of the healing time of colic. The present study showed that mothers used fennel-anise tea and suppositories as well as simethicone. It has been reported that a herbal tea prepared with chamomile, verbena, licorice, fennel and lemon balm reduces crying spells in infants with colic when it is given to the infant 3 times a day (23). Biagioli et al. (24) stated that herbal agents, sugar, dicyclomine and cimetropium bromide should not be recommended for colicky infants. The most frequently used drug therapy reported in the present study was the use of suppositories. In other studies, suppository use is rare $(25,26)$.

The mothers in the present study also gave olive oil (40.1\%), sherbet (27.2\%), and water with lemon juice (26.3\%) to their babies with infantile colic. In another study, $44.7 \%$ of the mothers gave sherbet, $2.1 \%$ gave water with lemon juice, and $1.4 \%$ gave olive oil to their infants (25). Akçam and Yılmaz (27) compared oral hypertonic glucose and sterile water, and found that the group receiving oral hypertonic glucose had significantly reduced colic symptoms than did the other group.

The rate of mothers presenting their infants to a hospital due to colic was $58.6 \%$ in the present study. Another study reported this rate to be $50.4 \%$ (25). Infantile colic can easily be managed by healthcare professionals, and the symptoms can be reduced with behavioral treatment without the need for drug therapy. Families should be informed about infantile colic, and assured that there is no underlying disease. They should also be told that infantile colic is a temporary condition that will spontaneously improve after approximately three months. The present study did not analyze the families' behavioral changes. This can be regarded as a limitation of this study.

Keefe et al. (28) conducted an intervention program (REST routine- weekly home visits by nurses) for healthy infants with colic. This program decreased the length of crying over the 8-week study period (0.9 hours) and infant irritability was resolved ( $<1$ hour of unexplained crying) in $62 \%$ of the treatment group. It is necessary to observe existing supervision practices and warn them about the colicky infants. A care strategy for reducing colic symptoms and maternal fatigue has the potential to improve family well-being (12). 
More than half of the mothers reported that they believed their infants suffered from colic. However, only $28.5 \%$ of infants met the definition of colic according to the Wessel criteria. The mean score obtained from the scale was found to be high. Most of the mothers used behavioral treatment to reduce the symptoms of colic. Drug therapies such as herbal tea or simethicone were also frequently used. In addition to these methods, the mothers also used cultural methods. More than half of the study sample had sought help from a hospital due to colic. Healthcare professionals play an important role in the management of colic symptoms.

Studies on the effectiveness of the most used behavioral methods can be planned. Healthcare professionals can be specialized to manage colic symptoms and provide support to mothers about the correct methods to be used. Rocking, massaging, swaddling, playing music and providing a quite environment are behavioral methods that every mother can easily apply. Healthcare professionals should support mothers using these methods and encourage them either by visiting the mother at home or by telephone counseling to create a healthy relationship between mother and baby.

\section{Study Limitations}

The lack of data on the discharge diagnosis of infants and mothers psychological state is one of the limitations of this study.

\section{Conclusions}

One out of every three or four babies in the study met the diagnosis of infantile colic according to Wessel's criteria. The average score obtained from The Infantile Colic scale is quite high. Mothers usually use behavioral methods to prevent and reduce colic symptoms, they also used pharmacological and traditional methods in this study.

\section{Ethics}

Ethics Committee Approval: The study was approved by the Ethics Committee of Faculty (IRB: 2015-82).

Informed Consent: Written informed consent was obtained from the participants before enrollment.

Peer-review: Enternally and internally peer-reviewed.

\section{Authorship Contributions}

Concept: N.A.D., Z.B., G.Ö.G., Design: N.A.D., Z.B., G.Ö.G., Data Collection or Processing: B.Y., T.A., M.A., Analysis or Interpretation: N.A.D., G.Ö.G., Literature Search: N.A.D., Z.B., G.Ö.G., B.Y., Writing: N.A.D., G.Ö.G.

Conflict of Interest: None of the authors had conflict of interest.
Financial Disclosure: The authors declared that this study received no financial support.

\section{References}

1. Kaley F, Reid V, Flynn E. The psychology of infant colic: A review of current research. Infant Ment Health I 2011; 32:526-41.

2. Savino F, Ceratto S, De Marco A, di Montezemolo LC. Looking for new treatments of Infantile Colic. Ital J Pediatr 2014; 40:53.

3. Zengin $\mathrm{H}$, Çınar N, Altınkaynak S. Approach to Infantile Colic Baby. I Hum Rhythm 2016;2:1-5.

4. Wessel MA, Cobb JC, Jackson EB, et al. Paroxysmal fussing in infacy, sometimes called "colic." Pediatrics 1954; 14:421-35.

5. Leung AKC, Lemay JF. Infantile colic: a review. I R Soc Promot Health 2004; 124:162-6.

6. Benninga MA, Nurko S, Faure C, Hyman PE, Robert ISC, Schechter NL. Childhood Functional Gastrointestinal Disorders: Neonate/ Toddler. Gastroenterology 2016; 150:1443-55.

7. Cohen-Silver J, Ratnapalan S. Management of Infantile Colic: A Review. Clin Pediatr 2009; 48:14-17.

8. Balcı S. The influence of white noise on colicky infants. [master's thesis]. Istanbul: Marmara University; 2006.

9. Alagöz H. Infantile colic: Ethyology and treatment. / Contemp Med 2013; 3:148-54.

10. Radesky IS, Zuckerman B, Silverstein $M$, et al. Inconsolable Infant Crying and Maternal Postpartum Depressive Symptoms. Pediatrics 2013; 131:1857-64.

11. Ellett MLC, Swenson M. Living with a colicky infant. Gastroenterol Nurs 2005; 28:19-25.

12. Kurth E, Kennedy HP, Spichiger E, et al. Crying babies, tired mothers: What do we know? A systematic review. Midwifery 2011; 27:187-94.

13. Helseth S, Begnum S. A comprehensive definition of infant colic: parents' and nurses' perspectives. J Clin Nurs 2002; 11:672-80.

14. Cirgin Ellett ML, Murphy D, Stroud L, et al. Development and psychometric testing of the infant colic scale. Gastroenterol Nurs 2003; 26:96-103.

15. Çetinkaya B, Başbakkal Z. The effectiveness of aromatherapy massage using lavender oil as a treatment for infantile colic. Int I Nurs Pract 2012; 18:164-9.

16. Saavedra M, Costa I, Garcias G, Horta BL, Tomasi E, Mendonça R. Infantile colic incidence and associated risk factors: a cohort study. I Pediatr 2003; 79:115-22.

17. Karabel $M$, Karabel $D$, Tayman $C$, et al. Evaluation of the treatment approaches and risk factors in infantile colic. Turkish J Pediatr Dis 2010; 4:12-7.

18. Lucassen PL, Assendelft W), Gubbels JW, van Eijk JT, douwes AC. Infantile colic: crying time reduction with a whey hydrolysate: A double-blind, randomized, placebo-controlled trial. Pediatrics 2000; 106:1349-54.

19. Cohen Engler A, Hadash A, Shehadeh N, Pillar G. Breastfeeding may improve nocturnal sleep and reduce infantile colic: potential role of breast milk melatonin. Eur / Pediatr 2012; 171:729-32. 
20. Çiftçi EK, Arikan D. Methods Used to Eliminate Colic in Infants in the Eastern Parts of Turkey. Public Health Nurs 2007; 24:50310.

21. Pease AS, Fleming PJ, Hauck FR, et al. Swaddling and the Risk of Sudden Infant Death Syndrome: A Meta-analysis. Pediatrics 2016; 137:20153275.

22. Studer K, Williams N, Antoniou G, et al. Increase in late diagnosed developmental dysplasia of the hip in South Australia: risk factors, proposed solutions. Med / Aust 2016; 204:240.

23. Savino F, Cresi F, Castagno E, et al. A randomized double-blind placebo-controlled trial of a standardized extract of Matricariae recutita, Foeniculum vulgare and Melissa officinalis (ColiMil) in the treatment of breastfed colicky infants. Phytother Res 2005; 19:335-40.
24. Biagioli E, Tarasco V, Lingua C, et al. Pain-relieving agents for infantile colic. In: Savino F, ed. Cochrane Database of Systematic Reviews 2016; CD009999.

25. Çiftçi EK, Arikan D. Methods Used to Eliminate Colic in Infants in the Eastern Parts of Turkey. Public Health Nurs 2007; 24:50310.

26. Garrison MM, Christakis DA. A systematic review of treatments for infant colic. Pediatrics 2000; 106:184-90.

27. Akçam M, Yılmaz A. Oral hypertonic glucose solution in the treatment of infantile colic. Pediatr Int 2006; 48:125-7.

28. Keefe MR, Barbosa GA, Froese-Fretz A, Kotzer AM, Lobo M. An intervention program for families with irritable infants. MCN Am I Matern Child Nurs 2005; 30:230-6. 